\title{
Understanding renal nuclear protein accumulation: an in vitro approach to explain an in vivo phenomenon
}

\author{
Lisanne Luks ${ }^{1}$ Marcia Y. Maier ${ }^{1,2} \cdot$ Silvia Sacchi $^{3,4} \cdot$ Loredano Pollegioni $^{3,4}$. \\ Daniel R. Dietrich ${ }^{1,2}$ (D)
}

\begin{abstract}
Proper subcellular trafficking is essential to prevent protein mislocalization and aggregation. Transport of the peroxisomal enzyme D-amino acid oxidase (DAAO) appears dysregulated by specific pharmaceuticals, e.g., the anti-overactive bladder drug propiverine or a norepinephrine/serotonin reuptake inhibitor (NSRI), resulting in massive cytosolic and nuclear accumulations in rat kidney. To assess the underlying molecular mechanism of the latter, we aimed to characterize the nature of peroxisomal and cyto-nuclear shuttling of human and rat DAAO overexpressed in three cell lines using confocal microscopy. Indeed, interference with peroxisomal transport via deletion of the PTS1 signal or PEX5 knockdown resulted in induced nuclear DAAO localization. Having demonstrated the absence of active nuclear import and employing variably sized mCherry- and/or EYFP-fusion proteins of DAAO and catalase, we showed that peroxisomal proteins
\end{abstract}

Lisanne Luks and Marcia Y. Maier contributed equally to this work and are listed in alphabetical order.

Daniel R. Dietrich

daniel.dietrich@uni-konstanz.de

1 Human and Environmental Toxicology, Department of Biology, University of Konstanz, Universitätsstrasse 10, 78457 Konstanz, Germany

2 Konstanz Research School Chemical Biology (KoRS-CB), University of Konstanz, Konstanz, Germany

3 Department of Biotechnology and Life Sciences, University of Insubria, Varese, Italy

4 Protein Factory Research Center, Politecnico di Milano and University of Insubria, Milan, Italy $\leq 134 \mathrm{kDa}$ can passively diffuse into mammalian cell nuclei-thereby contradicting the often-cited $40 \mathrm{kDa}$ diffusion limit. Moreover, their inherent nuclear presence and nuclear accumulation subsequent to proteasome inhibition or abrogated peroxisomal transport suggests that nuclear localization is a characteristic in the lifecycle of peroxisomal proteins. Based on this molecular trafficking analysis, we suggest that pharmaceuticals like propiverine or an NSRI may interfere with peroxisomal protein targeting and import, consequently resulting in massive nuclear protein accumulation in vivo.

Keywords Protein accumulation · Protein trafficking · Peroxisomal proteins $\cdot$ Nuclear diffusion $\cdot$ D-amino acid oxidase $\cdot$ Propiverine

\begin{tabular}{ll}
\multicolumn{2}{l}{ Abbreviations } \\
h/rCAT & Human/rat catalase \\
h/rDAAO & Human/rat D-amino acid oxidase \\
NES & Nuclear export signal \\
NLS & Nuclear localization signal \\
NTS & Nuclear translocation signal \\
PTS & Peroxisomal targeting signal \\
RNI & Relative nuclear intensity
\end{tabular}

\section{Introduction}

Massive intranuclear and cytoplasmic protein accumulations of the peroxisomal enzyme D-amino acid oxidase (DAAO) were found in rat proximal tubule epithelial cells after in vivo exposure to pharmaceuticals, e.g., propiverine and a norepinephrine/serotonin reuptake inhibitor (NSRI) (Dietrich et al. 2008; Radi et al. 2013). This druginduced accumulation was considered species- and organ 
specific (Dietrich et al. 2008). However, as the flavoenzyme DAAO (39 kDa) is mainly expressed in kidney, liver, and brain (Baudhuin et al. 1965; Verrall et al. 2007) and the fact that various forms of human disorders are attributed to mislocalization and aggregation of proteins (Hung and Link 2011), we considered it critical to better understand cellular handling of rat and human DAAO. Indeed, since DAAO produces hydrogen peroxide when degrading D-amino acids, mislocalization in the nucleus could provide for a serious threat to the cell integrity, therefore emphasizing that proper subcellular trafficking is essential for cell function and protein homeostasis. Although DAAO has gained increased attention with regard to its role in etiology and pathophysiology of schizophrenia and ALS in humans (Mitchell et al. 2010; Verrall et al. 2010), little is known about its physiological roles and subcellular trafficking, especially in the context of the unexpected nuclear localization after drug exposure. Since the nucleus represents a major quality control compartment in which misfolded proteins are degraded, impaired degradation can result in protein accumulation (Latonen 2011). As we have recently demonstrated that propiverine does not affect proteasomal activity in vitro (Luks et al. 2017), the observed nuclear and cytosolic DAAO accumulation in rat kidneys is unlikely due to an impaired proteasomal degradation. Thus, we hypothesized that altered intracellular trafficking could induce a shift from peroxisomal to nuclear transport of DAAO via two possible mechanisms:

(a) Interference with peroxisomal trafficking: DAAO harbors the peroxisomal targeting signal type 1 (PTS1) defined by the C-terminal conserved tripeptide Ser-HisLeu (SHL) (Gould et al. 1988). After cytosolic synthesis, PTS1-proteins are transiently present in the cytosol and subsequently transported into peroxisomes in a PEX5-dependent fashion (Smith and Aitchison 2013). Since nuclear DAAO accumulation in vivo is accompanied by a complete loss of peroxisomal DAAO (Luks et al. 2017), interference with the peroxisomal trafficking machinery (e.g., PEX5) may lead to a shift from peroxisomal to nuclear import.

(b) Activation of a putative nuclear import signal: Despite the fact that DAAO has no canonical nuclear localization signal (NLS), we identified a putative nuclear translocation signal (NTS). This import signal can facilitate nuclear import via importin 7 after phosphorylation of an S/T-P-S/T sequence (Chuderland et al. 2008).

While several drugs have been demonstrated to induce nuclear and cytosolic accumulations of DAAO in preclinical trials in rats, albeit with limited associated adverse pathology, the existence and relevance of such protein accumulations in humans remain obscure. For a better human risk assessment, we aimed to identify the molecular mechanism by which propiverine evokes adverse effects in vivo and used an in vitro approach comparing rat and human DAAO in cells of both species. We manipulated single trafficking pathways with which propiverine might interfere resulting in nuclear accumulation in vitro. Using site-directed mutagenesis of EYFP-tagged rat and human DAAO fusion proteins in combination with three different mammalian cells (human kidney HEK293, rat kidney proximal tubule WKPT, and human glioblastoma U87 cells), we altered intracellular protein transport and induced nuclear mislocalization of DAAO. We were able to demonstrate the omnipresence of DAAO in the nucleus of DAAO-overexpressing cells and showed that passive diffusion-but not active import-is causal for nuclear DAAO localization. In conjunction with the latter, our data imply that passive diffusion of molecules $\geq 40 \mathrm{kDa}$ is an inherent characteristic of the nuclear pore complex (NPC) in the mammalian cells tested.

\section{Materials and methods}

\section{Expression constructs}

Mammalian pEYFP-C3, pEYFP-rDAAO-C3, and pEYFPhDAAO-C3 expression vectors (Sacchi et al. 2008, 2011; Frattini et al. 2011) were used for overexpression of EYFPDAAO in HEK293, WKPT, and U87 cells. pEX-K4-HindIII-hCAT-EcoRI and pEX-K4-HindIII-rCAT-EcoRI were purchased from Eurofins Genomics and were used for subcloning of hCAT and rCAT cDNA into the pEYFP-C3 backbone. The bacterial expression vectors pET28-rDAAO and pET11b-hDAAO (Frattini et al. 2011; Romano et al. 2009) were used for expression of His-DAAO in BL21 (DE3) E. coli cells.

\section{Bacterial strains}

TOP10 chemically competent $E$. coli cells were purchased from Invitrogen and used as host for vector propagation and site-directed mutagenesis. BL21 (DE3) and chemically competent DH5 $\alpha$ E. coli cells were used for expression of recombinant His-tagged proteins and for molecular cloning of pEYFP-r/hCAT-C3, respectively.

\section{Site-directed mutagenesis}

FASTA sequences of rDAAO (O35078), hDAAO (P14920), rCAT (P04762), and hCAT (P04040) were derived from UniProtKB and used for signal sequence analysis. Sitedirected mutagenesis (Table 1) was performed as previously 
described (Edelheit et al. 2009). Briefly, the parental plasmid was amplified in two separate PCR reactions containing either forward or reverse primer carrying the desired mutation. Primers were purchased from Eurofins Genomics. For single-primer PCR, $500 \mathrm{ng}$ vector DNA, $40 \mathrm{pmol}$ forward or reverse primer, $0.2 \mathrm{mM}$ dNTPs, $1 \times$ complete pwo buffer, and 1.25 U pwo polymerase (Peqlab) were used in a $25 \mu \mathrm{L}$ PCR reaction in a $\mathrm{C} 100^{\mathrm{TM}}$ Thermal Cycler (BioRAD). Subsequently, the single-primer PCR reactions were combined, denatured and gradually reannealed as follows: $95{ }^{\circ} \mathrm{C}$ for $5 \mathrm{~min}, 90^{\circ} \mathrm{C}$ for $1 \mathrm{~min}, 80^{\circ} \mathrm{C}$ for $1 \mathrm{~min}$, $70{ }^{\circ} \mathrm{C}$ for $0.5 \mathrm{~min}, 60{ }^{\circ} \mathrm{C}$ for $0.5 \mathrm{~min}, 50{ }^{\circ} \mathrm{C}$ for $0.5 \mathrm{~min}$, $40{ }^{\circ} \mathrm{C}$ for $0.5 \mathrm{~min}$, and $37{ }^{\circ} \mathrm{C}$ for infinite. Afterwards, methylated parental DNA was digested using $30 \mathrm{U}$ DpnI (NEB) at $37{ }^{\circ} \mathrm{C} \mathrm{O} / \mathrm{N}$. After heat-inactivation of DpnI at $80{ }^{\circ} \mathrm{C}$ for $20 \mathrm{~min}, 50 \mu \mathrm{L}$ chemically competent E. coli Top10 were transformed via heat shock $\left(42{ }^{\circ} \mathrm{C}\right.$ for $\left.90 \mathrm{~s}\right)$ with $10 \mu \mathrm{L}$ of the DpnI-digested PCR mix. After 60 min of phenotypic expression, 300 and $700 \mu \mathrm{L}$ of bacterial suspension were spread on LB-plates (30 $\mu \mathrm{g} / \mathrm{mL}$ kanamycin) and grown $\mathrm{O} / \mathrm{N}$ at $37{ }^{\circ} \mathrm{C}$. $5-8$ colonies were grown in $5 \mathrm{~mL}$ LB-kan $\mathrm{O} / \mathrm{N}$ at $37{ }^{\circ} \mathrm{C}$ and $220 \mathrm{rpm}$. Plasmid preparation was performed according to manufacturers' instructions (GeneJet Plasmid Miniprep, Thermo Scientific). Sequencing was performed by Eurofins Genomics and analyzed using BLASTn-Nucleotide BLAST (NCBI).

\section{Cell culture}

HEK293 (human embryonic kidney) cells were purchased from the Leibniz Institute DSMZ-German Collection of Microorganisms and Cell Cultures. HEK293 cells were cultured in Dulbecco's modified Eagle's medium (DMEM) containing low glucose $(1 \mathrm{~g} / \mathrm{L})$ supplemented with $10 \%$ (v/v) fetal bovine serum (FBS) gold, $100 \mathrm{U} / \mathrm{mL}$ penicillin, and $0.1 \mathrm{mg} / \mathrm{mL}$ streptomycin. WKPT (WKY rat, kidney proximal tubule) cells were kindly provided by
Prof. Dr. Frank Thevenod (University of Witten/Herdecke, Germany) and were cultured in DMEM Nutmix F12 (Ham) containing $10 \%(\mathrm{v} / \mathrm{v})$ FBS, $100 \mathrm{U} / \mathrm{mL}$ penicillin and $0.1 \mathrm{mg} / \mathrm{mL}$ streptomycin, $1.2 \mathrm{mg} / \mathrm{mL} \mathrm{NaHCO} 3,5 \mu \mathrm{g} /$ $\mathrm{mL}$ insulin, $4 \mu \mathrm{g} / \mathrm{mL}$ dexamethasone, $0.01 \mu \mathrm{g} / \mathrm{mL}$ EGF, and $5 \mu \mathrm{g} / \mathrm{mL}$ apo-transferrin. Cell lines were routinely tested for mycoplasma contamination (GATC). Human U87 glioblastoma cells (ATCC) were cultured in DMEM supplemented with $10 \%$ fetal bovine serum, $1 \mathrm{mM}$ sodium pyruvate, $2 \mathrm{mM}$ L-glutamine, penicillin/streptomycin, and amphotericin $\mathrm{B}$ (Euroclone) at $37^{\circ} \mathrm{C}$ in $5 \% \mathrm{CO}_{2}$.

\section{Transfection}

For transient transfection, HEK293 and WKPT cells were seeded at cell densities of $4 \mathrm{E} 4$ cells $/ \mathrm{cm}^{2}$ and U87 at $1 \mathrm{E} 4$ cells $/ \mathrm{cm}^{2}$ into eight-well chamber slides (Sarstedt, \#94.6190.802). Chamber slides for HEK293 seeding were coated with poly-D-lysine. $24 \mathrm{~h}$ after seeding, cells were transfected with $2 \mu \mathrm{g}$ vector DNA using a 3:1 ratio of FuGENE transfection reagent (Promega) to DNA for HEK293 and a 4:1 ratio for WKPT and U87 cells. Finally, $25 \mu \mathrm{L}$ of transfection:DNA mix was added to $500 \mu \mathrm{L}$ medium per well for HEK293 and WKPT. For U87 cells, $20 \mu \mathrm{L}$ of transfection:DNA mix was added to $350 \mu \mathrm{L}$ medium per well.

\section{Immunocytochemistry}

$72 \mathrm{~h}$ after transfection, cells were washed once with warm PBS and fixed with warm $2 \%$ p-formaldehyde (PFA)/0.1\% Triton X-100 for $10 \mathrm{~min}$. For degradation inhibition experiments, cells were fixed $24 \mathrm{~h}$ after treatment with degradation inhibitors. After fixation, cells were washed twice with PBS and blocked with $1 \%(w / v)$ BSA in PBS for $30 \mathrm{~min}$ at RT. Primary antibody against PMP70 (1:400, rabbit polyclonal, Sigma-Aldrich, \#P0497), mono- and

Table 1 Nucleotide sequence for targeting signals modified via site-directed mutagenesis

\begin{tabular}{|c|c|c|c|}
\hline Construct & Signal sequence & DNA sequence & References \\
\hline \multicolumn{4}{|l|}{ PTS1 deletion } \\
\hline DAAO- $\triangle \mathrm{PTS}$ & $\Delta \mathrm{HL}$ & & Elgersma et al. (1996) \\
\hline CAT- $\triangle \mathrm{PTS}$ & $\triangle \mathrm{KANL}$ & & Purdue and Lazarow (1996), Trelease et al. (1996) \\
\hline \multicolumn{4}{|c|}{ Control for active nuclear import } \\
\hline NLS & PKKKRKVE & CCAAAAAAGAAACGTAAGGTCGAA & Kalderon et al. $(1984 a, b)$ \\
\hline \multicolumn{4}{|c|}{ Phosphomimetic NTS } \\
\hline EPE & $\mathrm{EPE}$ & GAGCCCGAG & Chuderland et al. (2008) \\
\hline \multicolumn{4}{|c|}{ Non-phosphorylatable NTS } \\
\hline APA & APA & GCCCCCGCC & Chuderland et al. (2008) \\
\hline \multicolumn{4}{|c|}{ Control for active nuclear export } \\
\hline NES & LAVKFAGLDL & CTGGCCGTGAAATTCGCCGGCCTGGACCTG & Bogerd et al. (1996), Fried and Kutay (2003) \\
\hline
\end{tabular}


polyubiquitinylated conjugates (FK2, 1:100, mouse monoclonal, Enzo, \#BML-PW8810-0100), SUMO1 (1:100, mouse monoclonal, Santa Cruz, \#sc-5308), and NOH61 (1:10, mouse monoclonal, Progen, \#651126) were diluted in blocking buffer and incubated $\mathrm{O} / \mathrm{N}$ at $4{ }^{\circ} \mathrm{C}$. Cells were then washed three times with PBS for 5 min and incubated with diluted Alexa Fluor ${ }^{\circledR} 647$ secondary antibody (1:1000, goat anti-rabbit IgG/rabbit anti-mouse IgG, Life Technologies, \# A-21244/A-21239) for $1 \mathrm{~h}$ at RT light-protected. After washing, HEK293 and WKPT cells were stained with Hoechst33342 $\left(\right.$ Calbiochem $^{\circledR}$ ) and U87 cells with DRAQ5TM (Thermo Scientific, \#62251) for $10 \mathrm{~min}$ at RT in the dark. Cells were washed three times with PBS and stored in PBS at $4{ }^{\circ} \mathrm{C}$ until imaging.

\section{Confocal microscopy}

Cells were fixed and analyzed 48-96 h after transfection. Best results were obtained after $72 \mathrm{~h}$ and used as representative data if not stated otherwise. HEK293 and WKPT cells were imaged using a point laser scanning confocal microscope LSM 880 (Zeiss) equipped with a $63.0 \times / 1.40$ oil immersion objective and ZEN software (Zeiss) (University of Konstanz). Analyses of U87 cells were carried out using an inverted laser scanning confocal microscope (TCS SP5, Leica Microsystems), equipped with a $63.0 \times 1.25$ NA plan apochromate oil immersion objective (University of Insubria, Varese). Multiple fluorophores were imaged via sequential scanning. All pictures are representative for at least three independent experiments $(n=3)$. If not stated otherwise, the same laser intensities were applied for control and treated cells. Note that for Figs. 3 and S3d, investigators were blinded to allocation during imaging.

\section{Recombinant proteins}

pET11b-His-hDAAO and pET28-His-rDAAO expression vectors were used to express His-DAAO in BL21(DE3) Star E.coli cells and purified as previously reported (Frattini et al. 2011; Molla et al. 2006). Using site-directed mutagenesis, His-h/rDAAO- $\triangle$ PTS mutants were generated from pET11b-His-hDAAO and pET28-His-rDAAO expression vectors, respectively (see above).

\section{Oxygen consumption assay}

Activity of DAAO was measured by oxygen consumption using a Clark electrode at $25^{\circ} \mathrm{C}$ in $75 \mathrm{mM}$ sodium pyrophosophate buffer ( $\mathrm{pH} 8.5$ ), $28 \mathrm{mM}$ (hDAAO) or $1 \mathrm{M}$ D-alanine (rDAAO), and $200 \mu \mathrm{M}$ FAD (hDAAO) or $5 \mu \mathrm{M}$ FAD (rDAAO). Higher FAD concentrations for hDAAO are necessary due to a $\sim 10 \times$ lower binding affinity for FAD.
Higher D-alanine concentrations were used for rDAAO due to lower substrate specificity (Frattini et al. 2011).

\section{Far- and near-UV circular dichroism (CD) spectral analysis}

Spectroscopic experiments were performed as reported previously (Caldinelli et al. 2009) in $20 \mathrm{mM}$ Tris- $\mathrm{HCl}$ (pH 8.0), $100 \mathrm{mM} \mathrm{NaCl}, 10 \%$ glycerol, and $5 \mathrm{mM}$ 2-mercaptoethanol. Note that for experiments with hDAAO, the buffer contained additional $40 \mu \mathrm{M}$ FAD to favor holoenzyme production resulting in the typical FAD spectrum as observed in the near-UV spectrum of hDAAO (Fig. 1d, bottom, light gray). CD spectra were recorded on a Jasco $\mathrm{J}-810$ spectropolarimeter at $15^{\circ} \mathrm{C}$.

\section{Knockdown of PEX5}

SMARTpool PEX5 siRNA (L-015788-00-0005) and ON-TARGETplus non-targeting pool siRNA (D-00181010-05) were purchased from Dharmacon. HEK293 cells were transfected according to the manufacturer's instructions with a final concentration of $10 \mathrm{nM}$ siRNA and $4 \mu \mathrm{L} /$ well transfection reagent. For protein analysis of PEX5 knockdown, wild-type or stably transfected HEK293 cells expressing rDAAO or hDAAO were seeded in a six-well plate with a density of $3.3 \mathrm{E} 4$ cells $/ \mathrm{cm}^{2}$ and harvested 48-72 h after siRNA knockdown. For confocal analysis, wild-type HEK293 cells were seeded onto cover slips in a six-well plate, medium was removed $24 \mathrm{~h}$ after siRNA transfection, and cells were subsequently transfected with EYFP-DAAO. $48 \mathrm{~h}$ after transfection, cells were fixed and stained for confocal microscopy. Note that non-treated and negative siRNA pool-treated cells show comparable PEX5, DAAO, and actin level.

\section{SDS-PAGE and Western blotting}

For protein analysis, cells were washed once with cold PBS, scraped off in PBS, and collected in a $1.5 \mathrm{~mL}$ reaction tube on ice. Pelleted cells were lyzed in RIPA buffer (50 mM Tris- $\mathrm{HCl}, 150 \mathrm{mM} \mathrm{NaCl}, 0.1 \%$ SDS, $0.5 \%$ sodium deoxycholate, $1 \%$ Triton $\mathrm{X}-100$, and Halt ${ }^{\mathrm{TM}}$ Protease Inhibitor Cocktail (Thermo Scientific)) for $10 \mathrm{~min}$ on ice. After vortexing, lysates were centrifuged at $16000 \times \mathrm{g}$ for $10 \mathrm{~min}$. The protein concentration in the supernatant was determined using the BCA Protein Assay (\#23225, Thermo Scientific). Proteins were denatured by boiling for $5 \mathrm{~min}$ at $95{ }^{\circ} \mathrm{C}$ in SDS buffer (187.5 mM Tris- $\mathrm{HCl} \mathrm{pH} 8.8,10 \%$ (v/v) glycerol, 2\% (w/v) SDS, $20 \%$ (v/v) 2-mercaptoethanol, and $1 \%(\mathrm{w} / \mathrm{v})$ bromophenol blue). $20 \mu \mathrm{g}$ protein per lane was loaded onto a $12 \%$ gel, separated by SDS-PAGE and blotted onto a nitrocellulose membrane. The membrane 
was blocked with 5\% (w/v) milk powder in TTBS (100 mM Tris-HCl, $150 \mathrm{mM} \mathrm{NaCl}, 0.1 \%$ (v/v) Tween 20, $\mathrm{pH}$ 7.6) for $40 \mathrm{~min}$. The following antibodies were diluted in $5 \%$ milk powder and incubated $\mathrm{O} / \mathrm{N}$ at $4{ }^{\circ} \mathrm{C}$ : anti-PEX5 (1:1000, mouse, Abcam, \#125689), anti-DAAO (1:5000, sheep, Antibodies online, \#94967), and anti- $\beta$-actin (1:2000, mouse, Sigma-Aldrich, \#A2228). After removal of unbound primary antibodies, membranes were incubated for $1 \mathrm{~h}$ at RT with peroxidase-conjugated secondary antibodies (antimouse IgG-peroxidase, 1:80,000, Sigma-Aldrich, \#A9044; anti-sheep IgG-peroxidase, 1:10,000, Sigma-Aldrich, \#A3415) and signals were detected by enhanced chemiluminescence (ECL ultra, Lumigen, \#TMA-6).

\section{Native PAGE}

Cells were harvested as described above, resuspended in cold lysis buffer (50 mM Tris- $\mathrm{HCl} \mathrm{pH} 7.5,150 \mathrm{mM} \mathrm{NaCl}$, $0.5 \mathrm{mM}$ EDTA pH 8, 0.5\% NP-40, $1 \mathrm{mM}$ PMSF, and Halt $^{\mathrm{TM}}$ protease inhibitor cocktail (Thermo Scientific)) and lyzed on ice by passing repeatedly through a $27 \mathrm{G}$ needle. After centrifugation at $20,000 \times g$ for $10 \mathrm{~min}$ at $4{ }^{\circ} \mathrm{C}$, the supernatant was subjected to BCA Protein Assay (Thermo Scientific, \#23225) to determine protein levels. Proteins were denatured by boiling for $5 \mathrm{~min}$ at $95{ }^{\circ} \mathrm{C}$ in native PAGE sample buffer (62.5 mM Tris- $\mathrm{HCl} \mathrm{pH} 6.8,25 \%$ (v/v) glycerol, and $0.1 \%(\mathrm{w} / \mathrm{v})$ bromophenol blue). $20 \mu \mathrm{g}$ total protein was separated by $12 \%$ SDS-PAGE and blotted onto a nitrocellulose membrane. EYFP-fusion proteins were detected using anti-GFP antibody (1:1000 in 5\% milk, mouse, Roche, \#1814460001) and anti-mouse IgG-peroxidase as described above. Note that EYFP-only (30 kDa) and hDAAO (135 kDa) were used on every blot as "protein size marker".

\section{Inhibition of protein degradation and quantitative imaging}

For high-content screening, HEK293 cells stably expressing hDAAO or rDAAO (similar expression levels) were seeded into a 96-well plate coated with poly-D-lysine. $24 \mathrm{~h}$ after seeding, cells were treated either with DMSO control, $50 \mu \mathrm{M}$ chloroquine (Sigma-Aldrich, \#C6628), or $1 \mu \mathrm{M}$ epoxomicin (Santa Cruz, \#sc-201298). Note that $0.5 \mu \mathrm{M}$ epoxomicin was used for confocal microcopy. Cells were fixed $24 \mathrm{~h}$ after treatment as described above, stained with Hoechst33342 (Calbiochem), and nuclear-cytoplasmic fluorescence was measured using Cellomics (ArrayScan and CellInsight, Thermo Scientific) as described previously (Henn et al. 2011). Briefly, the border of the nuclear stain ("circle") was used to create a mask for identification of nuclear localization and an annulus mask ("ring") was used to assess cytosolic localization. The total intensity of EYFP inside both the masks was averaged per well by analyzing 200 cells per well. Relative fluorescence units (RFU) were calculated based on the following equation and normalized to cell count:

$\frac{\text { mean intensity (circle) }}{\text { mean intensity (ring) }+ \text { mean intensity (circle) }} \times 100 \%$.

\section{Data handling and statistical analyses}

If images are labeled with "DAAO", experiments were performed for both $\mathrm{rDAAO}$ and hDAAO. However, results can be interpreted equally for both hDAAO and rDAAO constructs. Image analysis was performed using the (Fiji Is just) ImageJ software. The Pearson's correlation coefficient ( $r$ ) was determined using Fiji Colok 2 analysis of single cells (whole cells were used if not otherwise indicated, e.g., $r_{\text {cyt }}$ ) using the following settings: bisection threshold regression and point spread function (PSF) of 12 and 100 Costes randomizations. Intensity line plot profiles were obtained from Fiji Multi Plot analysis. For illustration, pixel intensities were normalized to min and max values (represented as \%). The relative nuclear intensity (RNI) was calculated based on mean gray intensities for single cells and calculated as follows: RNI $=$ intensity $_{\text {nucleus }}$ /intensity $_{\text {cytosol }}$. On average, five biological replicates (36 cells) for HEK293 and four biological replicates (50 cells) for WKPT and three biological replicates (65 cells) for U87 were used for each mutant. GraphPad Prism 5 was used for statistical analysis and PyMOL for conformational analysis.

\section{Online supplemental material}

$\mathrm{S} 1$ shows that rDAAO- $\triangle \mathrm{PTS}$ is correctly folded and active, and is localized in the nucleus and cytosol in WKPT cells. PEX5 knockdown leads to a decrease of the Pearson's coefficient of PMP70 and DAAO. S2 shows the cross-talk of PTS- and NLS-targeting signals independent of their localization within the DAAO sequence. S3 shows native PAGE of DAAO and CAT oligomeric constructs and the quantification and confocal analysis of the constructs in WKPT cells.

\section{Results}

\section{Impaired peroxisomal trafficking leads to cytosolic and enriched nuclear DAAO}

The majority of peroxisomal proteins like DAAO is synthesized in the cytosol and post-translationally transported via their C-terminal PTS1 into peroxisomes. To better understand how DAAO might enter the nucleus - a phenomenon observed after in vivo administration of several 
drugs (Dietrich et al. 2008; Radi et al. 2013)—we manipulated peroxisomal trafficking of DAAO. First, we investigated the subcellular localization of EYFP-tagged human and rat DAAO overexpressed in HEK293, WKPT and U87 cells, usually expressing DAAO protein at levels below detection, using confocal microscopy. As expected, wildtype human (hDAAO, Fig. 1a) and rat DAAO (rDAAO, Fig. S1a) showed peroxisomal localization, as indicated by co-localization with the peroxisomal membrane protein 70 (PMP70). Indeed, Pearson's correlation coefficient ( $r)$ values obtained for hDAAO $(r=0.81$, Fig. 1a) and
rDAAO ( $r=0.79$, Fig. S1a) corroborated the latter finding. We visualized the localization of EYFP-DAAO (yellow), PMP70 (red), and Hoechst (blue) using a line plot profile (Fig. 1a). The pixel intensity of EYFP-DAAO and PMP70 along the arrow-depicted in the merge paneldisplayed distinct overlapping spikes, where the line passes through peroxisomes (Fig. 1a). Next, we manipulated the peroxisomal import of DAAO by deleting the two C-terminal amino acids of the PTS1 sequence (hereinafter referred to as $\triangle \mathrm{PTS}$ ) by site-directed mutagenesis. The latter resulted in a diffuse nuclear and cytosolic
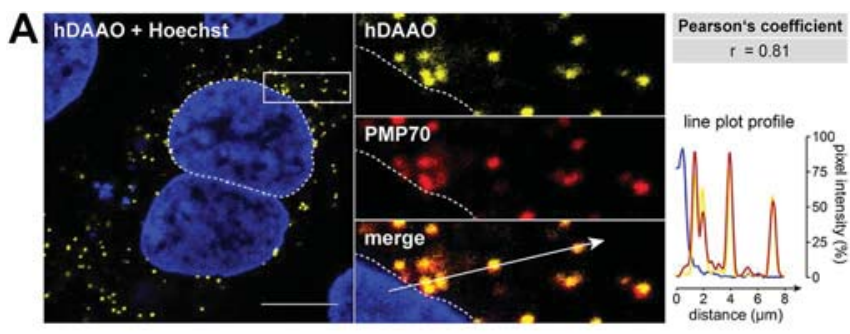

C
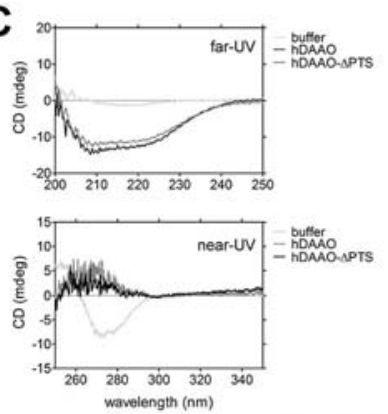

$\mathbf{G}$

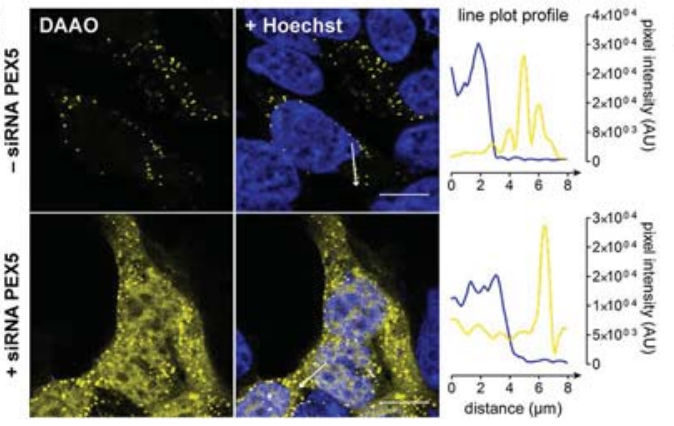

E
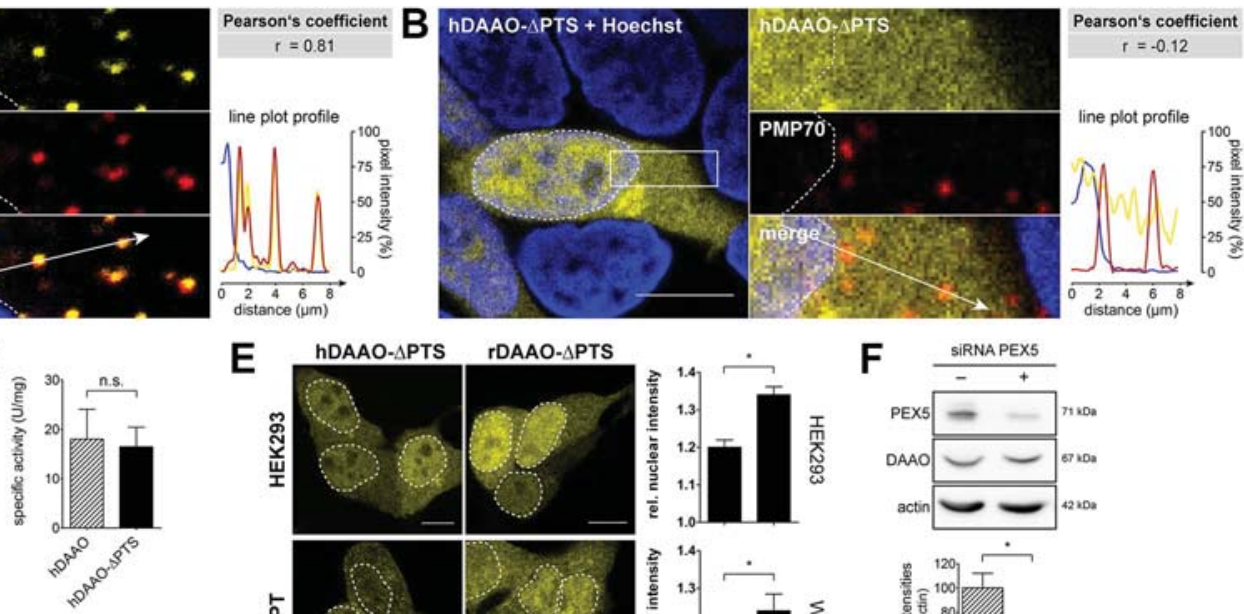

ชั
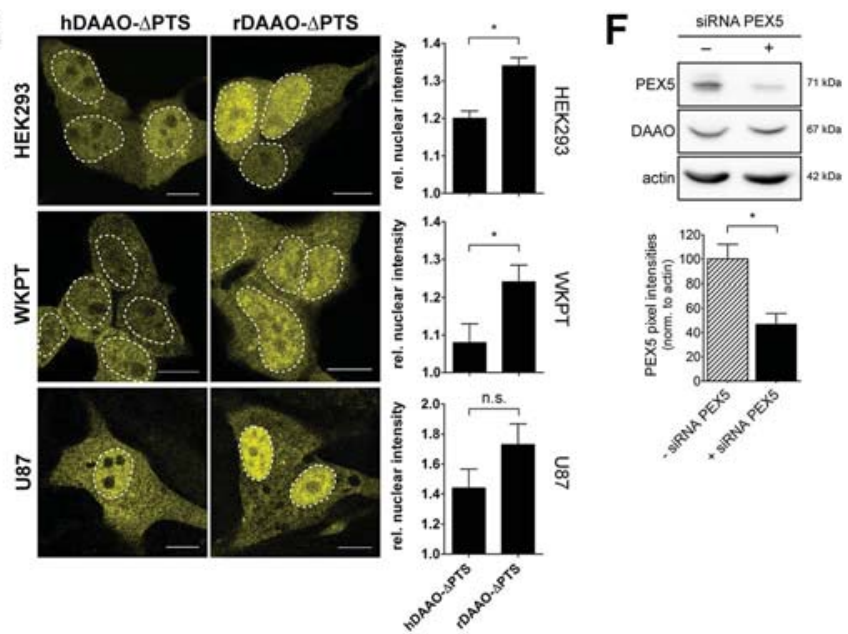

Fig. 1 Interference with peroxisomal import promotes nuclear localization of DAAO. Confocal microscopy of transiently transfected HEK293 expressing EYFP-tagged a hDAAO, b hDAAO$\triangle$ PTS. Nuclei are labeled with Hoechst33342 and are indicated by dashed lines. Pearson's correlation coefficient $(r)$ is used to determine co-localization of EYFP-DAAO and peroxisomal marker protein PMP70. Line plot profile displays the fluorescence intensity (in $\%$ ) of Hoechst (blue), PMP70 (red) and EYFP (yellow) along the arrow (distance in $\mu \mathrm{m}$ ). c Representative far-UV (upper figure) and near-UV (lower figure) circular dichroism (CD) spectra of recombinant His-hDAAO and His-hDAAO- $\triangle \mathrm{PTS}$. d Enzymatic activity of His-hDAAO and His-hDAAO- $\triangle$ PTS1 determined using oxygen consumption. Mean \pm SEM, $n=3$. Unpaired $t$ test, ns $=$ not significant. e Confocal microscopy of HEK293, WKPT and U87 cells transiently transfected with EYFP-h/rDAAO- $\triangle$ PTS. Quantification of relative nuclear intensity of EYFP signal (intensity nucleus $_{\text {intensity }}$ cell). Mean \pm SEM, $n=5$ for HEK293, $n=4$ for WKPT and $n=3$ for U87 cells. Unpaired $t$ test, $* p<0.05$, ns $=$ not significant. f Representative Western blot of PEX5 knockdown using siRNA in HEK293 cells stably expressing EYFP-hDAAO. Actin and DAAO were used as controls. Quantification of knockdown efficiency in wild-type, human and rat DAAO expressing cells presented as mean $\pm \mathrm{SEM}$, $n=3$. Unpaired $t$ test, $* p<0.05$. g Confocal analysis and line plot profile of HEK293 cells expressing EYFP-DAAO $24 \mathrm{~h}$ after knockdown of PEX5. h/rDAAO = EYFP-tagged human/rat DAAO. PMP70 = peroxisomal membrane protein 70. PTS $=$ peroxisomal targeting signal. PEX5 = peroxisomal biogenesis factor 5. Scale bar $10 \mu \mathrm{m}$ 
distribution of hDAAO (Fig. 1b) and rDAAO (Fig. S1b). Interestingly, we observed a higher EYFP signal in the nucleus, thus suggesting directed nuclear transport of DAAO. The Pearson's $r$ values for hDAAO- and rDAAO$\triangle \mathrm{PTS}(r=-0.12$ and $r=-0.05)$ indicated the lack of DAAO- $\triangle$ PTS and PMP70 co-localization (Figs. 1b, S1b). Indeed, the line plot profile confirmed that DAAO- $\Delta$ PTS is predominantly localized in the nucleus, indicated by a higher EYFP pixel intensity inside the nucleus that then gradually decreased towards the cytosol (Figs. 1b, S1b). Moreover, perinuclear protein accumulations were formed that most likely represent aggresomes (Garcia-Mata et al. 1999) (Figs. 1b, S1b). Nuclear import secondary to misfolding or loss-of-function (Park et al. 2013) was considered unlikely since DAAO- $\triangle$ PTS mutants were not altered in their secondary and tertiary protein structures as well as in their enzymatic activity (Figs. 1c, d, S1c, d). These results demonstrate that impairment of correct peroxisomal targeting and import provoked nuclear DAAO mislocalization.

To better characterize the subcellular localization of $\triangle$ PTS variants in HEK293, WKPT, and U87 cells, we quantified the nuclear localization by calculating the relative nuclear intensity $\left(\mathrm{RNI}=\right.$ intensity $_{\text {nucleus }}$ /intensity $_{\text {cell }}$ ) (Fig. 1e). Both confocal analysis and signal quantification revealed an enrichment of EYFP signal in the nucleus (RNI > 1). Of importance, appears the finding that the nuclear signal was invariably higher for rDAAO$\triangle$ PTS than for hDAAO- $\triangle$ PTS, both in human-derived HEK293 and U87, and rat-derived WKPT cells, suggesting a cell line independent albeit protein-species dependent effect (Fig. 1e). To strengthen the hypothesis that disturbed peroxisomal trafficking is causal for nuclear localization of DAAO, we partially silenced PEX5, the cytosolic receptor for PTS1 proteins. siRNA silencing resulted in a significant downregulation of PEX5 protein $(53 \%)$, while affecting neither DAAO nor actin protein expression (Fig. 1f), and led to a diffuse nuclear and cytosolic localization of DAAO (Fig. 1g, +siRNA). The line plot profile confirmed a higher nuclear EYFP signal in PEX5-silenced cells (Fig. 1g, lower panel). The remaining PEX5 still accounted for some peroxisomal transport of DAAO, as quantified by co-localization analysis with PMP70 $\left(r_{- \text {siRNA }}=0.6 ; r_{+ \text {siRNA }}=0.29\right)($ Fig. S1e $)$. Taken together, we were able to induce nuclear DAAO localization-to date only observed in vivo (Dietrich et al. 2008; Radi et al. 2013)_by preventing peroxisomal targeting and import of the overexpressed protein via deletion of the PTS1 signal or suppression of the PEX5 receptor, respectively. Thus, the enriched nuclear DAAO and the absence of an NLS in the DAAO sequences beg the question, whether an NTS could be responsible for active nuclear import.

\section{Interplay of multiple targeting signals and their influence on subcellular trafficking}

Although having $80 \%$ sequence homology, rDAAO and hDAAO may differ in their repertoire and functionality of signal sequences. Indeed, we discovered different putative and accessible NTS (TPx) variants within the DAAO sequences: $\mathrm{T}_{117}-\mathrm{P}_{118}-\mathrm{S}_{119}$ for $\mathrm{rDAAO}$ and $\mathrm{T}_{118}-\mathrm{P}_{119}-\mathrm{R}_{120}$ for $\mathrm{hDAAO}$ (Fig. 2a). Since phosphorylation of an arginine (e.g., $\mathrm{R}_{120}$ ) is less frequent than phosphorylation of serine or threonine (Ciesla et al. 2011), nuclear transport of hDAAO may be less efficient, thus possibly explaining the observed lower nuclear accumulation for hDAAO than for rDAAO (Fig. 1e). We replaced serine $\left(\mathrm{S}_{119}\right)$ in rDAAO, arginine $\left(\mathrm{R}_{120}\right)$ in hDAAO, and threonine $\left(\mathrm{T}_{117 / 118}\right)$ with glutamate $(\mathrm{E})$ via site-directed mutagenesis to mimic phosphorylation and thus activation of the NTS (Fig. 2a, b) (Chuderland et al. 2008). The phosphomimetic EPE-DAAO mutant was exclusively found in peroxisomes (Fig. 2b), with a similar Pearson $r$ value $(r=0.77)$ and line plot profile as wild-type DAAO ( $r=0.81)$ (Fig. 1a). To avoid potential multiple targeting (Ast et al. 2013), we deleted the PTS1 of activated (EPE-DAAO) and inactivated (APADAAO) NTS constructs (Fig. 2a). Inactivation of the NTS was achieved by replacing glutamate with non-phosphorylatable alanine (A) (Chuderland et al. 2008). The activity of the NTS had no effect on the subcellular distribution of DAAO (Fig. 2b-d), i.e., it was comparable to the DAAO- $\triangle$ PTS1 mutant (Fig. 1b). By adding a classic monopartite NLS (PKKKRKVE) N-terminally of DAAO either possessing an active (Fig. 2e) or deleted PTS1 (Fig. 2f), we showed the competition of NLS and PTS signals and thereby confirmed the influence of multiple targeting signals. Note that the relative position of NLS and PTS had no influence on protein localization (Fig. S2a, b (a, b, c)), while the PTS1 is only accessible when placed at the very C-terminus (Fig. S2a, b (d)). In addition, nuclear DAAO localization observed for the $\triangle$ PTS mutants (Figs. 1b, S1b) was significantly less compared to when a classical NLS was added (Figs. 2f, S2d-g). We thus conclude that the putative NTS in DAAO is not functional and the observed nuclear localization of DAAO most likely does not result from active import via an internal nuclear trafficking signal. Contrary to our initial hypothesis and currently published evidence, we questioned whether nuclear localization of DAAO could have resulted from passive diffusion when import into the peroxisomes is inhibited.

\section{The nuclear barrier is not rigid, allowing peroxisomal proteins to enter the nucleus depending on their molecular weight}

Contrary to the fact that past research suggested that only small proteins $\leq \sim 40 \mathrm{kDa}$ can passively diffuse through nuclear pore complexes (NPCs) (Paine and Feldherr 1972; 

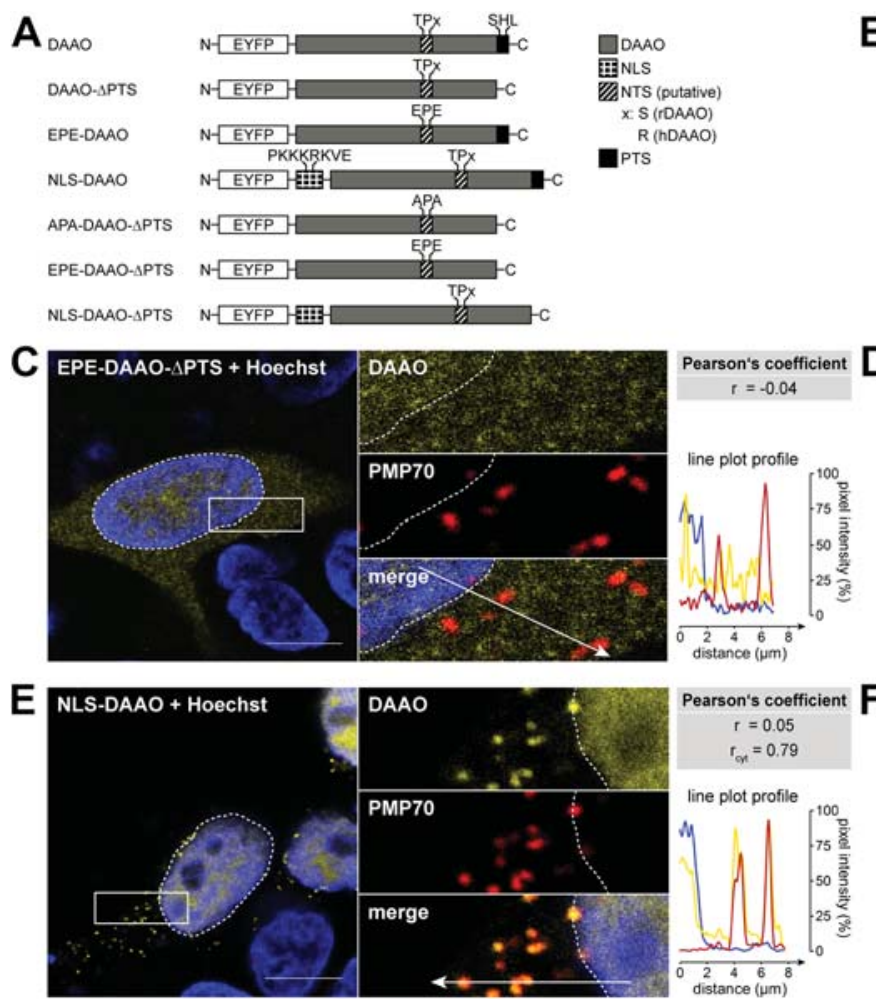

Fig. 2 Involvement of NTS variants in nuclear localization of DAAO. a Schematic representation of EYFP-DAAO constructs with N-terminal EYFP-tag, C-terminal PTS1 (SHL), putative NTS (TPx; $x=S$ in rDAAO; $x=R$ in hDAAO) and classical monopartite NLS (PKKKRKVE). Confocal microscopy of transiently transfected HEK293 cells expressing b EPE-DAAO, phosphomimetic NTS mutant; c EPE-DAAO- $\triangle$ PTS, phosphomimetic NTS and $\triangle$ PTS mutant; d APA-DAAO- $\triangle$ PTS, non-phosphorylatable NTS

Keminer and Peters 1999; Ma et al. 2012; Knockenhauer and Schwartz 2016), our observations would imply that also much larger proteins passively diffuse into the nucleus. Indeed, the size difference of EYFP-rDAAO (a $67 \mathrm{kDa}$ monomer) and hDAAO (a $135 \mathrm{kDa}$ dimer (Frattini et al. 2011)) could explain the greater nuclear enrichment of rDAAO- $\triangle$ PTS compared to hDAAO- $\triangle \mathrm{PTS}$ (Fig. 1c). To corroborate the latter as well as to better understand sizedependent nuclear diffusion, we increased the mass of the DAAO- $\triangle$ PTS mutants from 67 to $94 \mathrm{kDa}$ (rDAAO) and from 135 to $189 \mathrm{kDa}(\mathrm{hDAAO})$ by inserting mCherry (mCh, $27 \mathrm{kDa}$ ) into the DAAO constructs (Fig. 3a (f, i), b). Catalase (CAT) served as an additional example for a peroxisomal protein yet with a higher molecular weight (Lazarow and de Duve 1973; Vainshtein et al. 1981), thus allowing us to rule out protein-specific effects (Fig. 3a (j-m), b).

The diffusion capability of the different constructs was calculated via the relative nuclear intensity (RNI $=$ intensity $_{\text {nucleus }}$ /intensity ${ }_{\text {cell }}$ ) (Fig. 3c). EYFP-only (Fig. 3c, d (a)) served as diffusion control and, interestingly, demonstrated
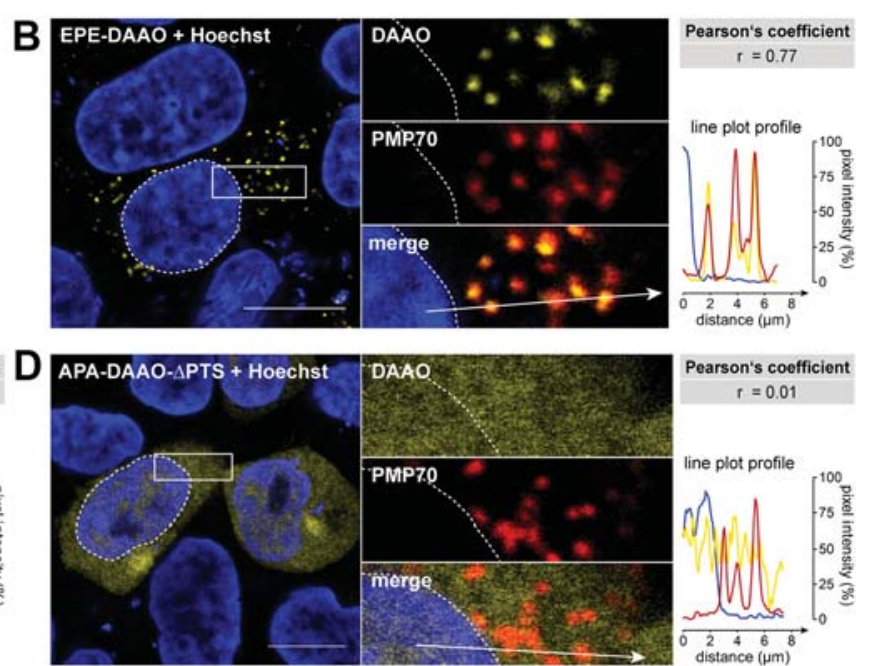

Pearson's coefficient $t=0.01$
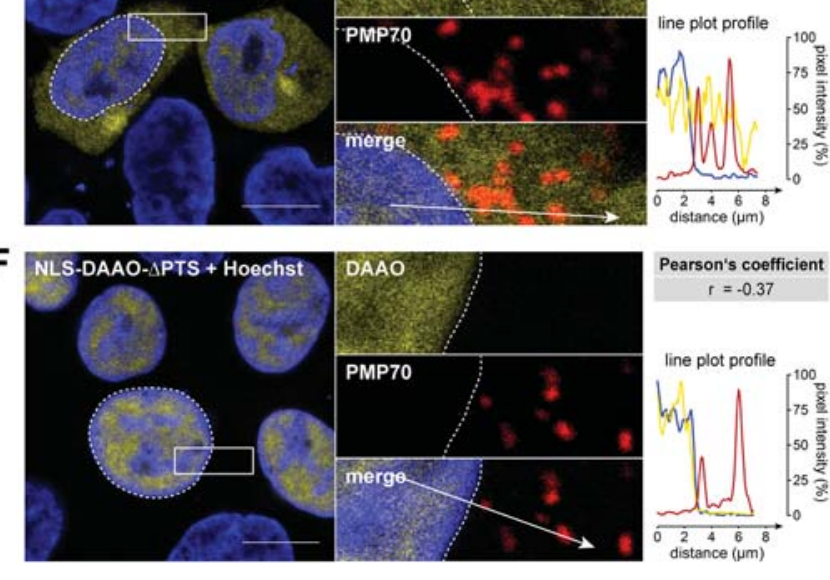

and $\triangle$ PTS mutant; e NLS-DAAO, control for active nuclear and concomitant peroxisomal import; $r_{\text {cyt }}=r$ value for cytosolic region only and f NLS-DAAO- $\triangle$ PTS, control for active nuclear import. Nuclei are labeled with Hoechst33342 and are indicated by dashed lines. DAAO = EYFP-tagged human/rat DAAO. PMP70 = peroxisomal membrane protein 70 . PTS $=$ peroxisomal targeting signal. NTS = nuclear translocation signal. NLS $=$ nuclear localization signal. Scale bar $10 \mu \mathrm{m}$

an RNI of 1.27, indicating that the $30 \mathrm{kDa}$ EYFP protein is enriched in the nuclear compartment. Indeed, the nucleus features a higher heterogeneity leading to reduced mobility of proteins (Baum et al. 2014), thus most likely explaining the trapping of EYFP inside the nucleus. As an active import control, we fused the classic, monopartite NLS to DAAO and observed - as expected — an exclusive localization of NLS-DAAO in the nucleus $\left(\mathrm{RNI}_{\mathrm{NLS}-\mathrm{hDAAO}}=1.79\right.$; $\mathrm{RNI}_{\mathrm{NLS}-\mathrm{rDAAO}}=1.67$ ) (Fig. 3c, d (b, c)). Wild-type r/hDAAO solely localized to peroxisomes; therefore, the $\mathrm{RNI}$ is $<1\left(\mathrm{RNI}_{\mathrm{hDAAO}}=0.78\right.$; $\left.\mathrm{RNI}_{\mathrm{rDAAO}}=0.77\right)($ Fig. $3 \mathrm{c}, \mathrm{d}$ $(\mathrm{d}, \mathrm{g})$ ). Deletion of the PTS1 resulted in nuclear enrichment of both hDAAO- $\triangle$ PTS (RNI = 1.2) and the rDAAO- $\triangle$ PTS $(\mathrm{RNI}=1.34)$ but strikingly is not significantly different to EYFP-only distribution (Fig. 3c, d (e, h, a)). Contrary to the postulated threshold of $\leq \sim 40 \mathrm{kDa}$ for passive diffusion, the dimeric $134 \mathrm{kDa}$ hDAAO- $\triangle \mathrm{PTS}$ mutant passively diffused into the nucleus-albeit less efficiently than the $67 \mathrm{kDa}$ rDAAO- $\triangle$ PTS mutant (Fig. 3c (h, e)). Using native PAGE, we confirmed the reported multimeric states of our constructs verifying that hDAAO exists as dimer and $\mathrm{rDAAO}$ 


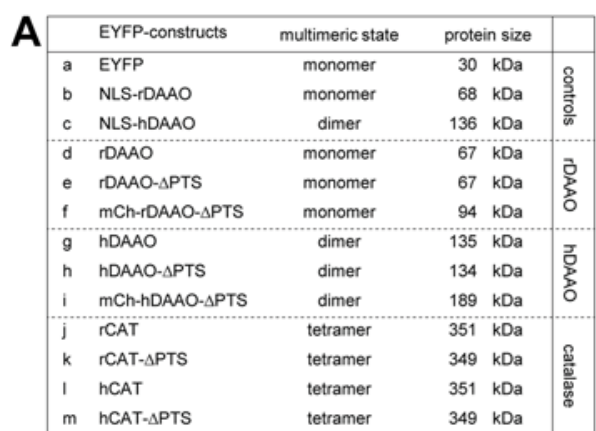

c
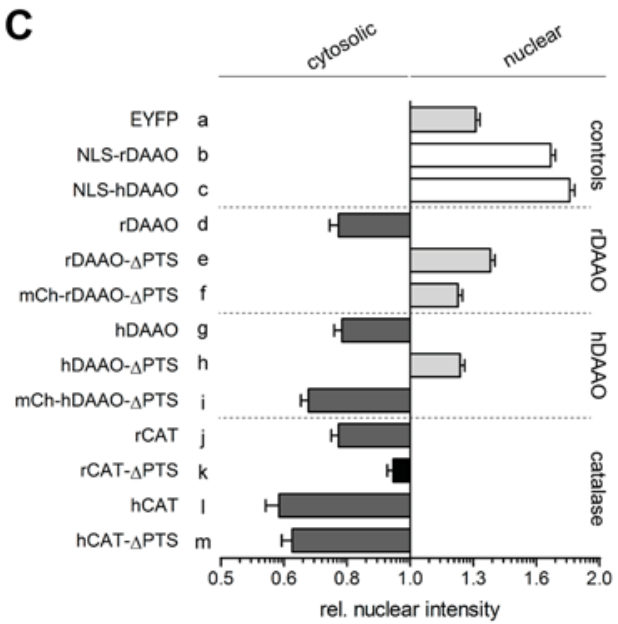

B

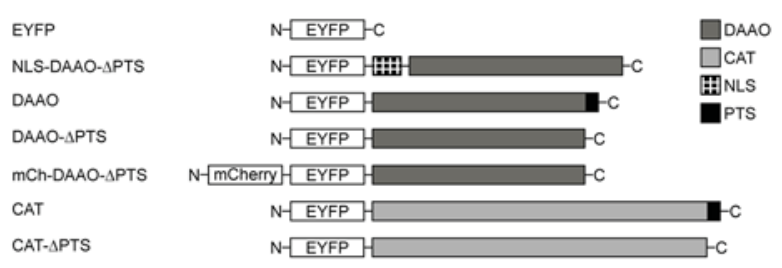

D
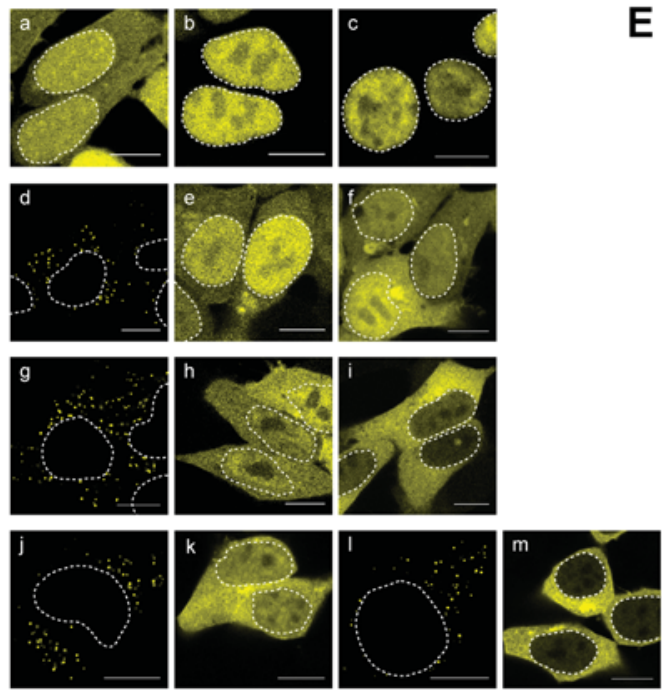

E

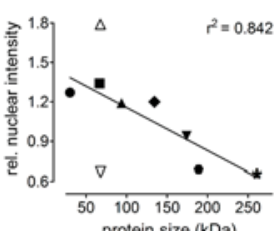
protein size $(\mathrm{kDa})$

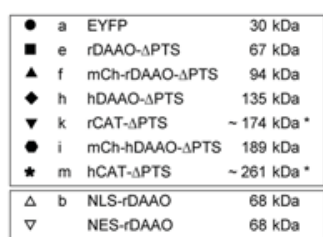

Fig. 3 Passive diffusion into the nucleus decreases with increasing molecular weight. a Table of EYFP constructs giving the multimeric state and protein mass. b Schematic representation of EYFP-DAAO and -CAT constructs with N-terminal EYFP- or mCherry-tag, C-terminal PTS1 (SHL) and classical monopartite NLS (PKKKRKVE). c Quantification of relative nuclear intensity (RNI) of EYFP signal (intensity nucleus $_{\text {intensity }}$ cell $)$ in HEK293 cells. Mean \pm SEM, $n=5$ (35 cells). One-way ANOVA + Tukey's post-test, different colored bars are significantly different at $p<0.05$. d Confocal microscopy

as monomer in our cell systems (Fig. S3a). The second band of rDAAO on the native PAGE might be a post-translational modification which was not observed for $\mathrm{hDAAO}$ (Fig. S3a). The 94 kDa mCh-rDAAO- $\triangle$ PTS construct was also found to accumulate in the nucleus (RNI $=1.19$ ), comparable to hDAAO- $\triangle$ PTS (Fig. 3c, d (f, h)). However, increasing the molecular mass to $189 \mathrm{kDa}$ (i.e., with the dimeric mCh-hDAAO- $\triangle \mathrm{PTS}$ construct) resulted in a significant exclusion from the nucleus $(\mathrm{RNI}=0.69$; Fig. 3c, d (i)). As expected, the catalase constructs ( $\geq 349 \mathrm{kDa}$; Fig. 3a) did not show nuclear accumulation, irrespective of the PTS deletion, whereby the nuclear exclusion was comparable to that observed for mCh-hDAAO- $\triangle \mathrm{PTS}$ (Fig. 3d (k, m, i)). However, hCAT- $\triangle$ PTS displayed a stronger nuclear exclusion $(\mathrm{RNI}=0.65)$ than $\mathrm{rCAT}-\Delta \mathrm{PTS}$ $(\mathrm{RNI}=0.94)$, although both protein species were reported to occur as $\sim 350 \mathrm{kDa}$ tetramers (Fig. 3a, c, d (k, m)) (Lazarow and de Duve 1973; Vainshtein et al. 1981). Native of transiently transfected HEK293 expressing EYFP constructs as described in $\mathbf{a}$. Nuclei are indicated by dashed lines. e Linear regression analysis between RNI and molecular size (kDa). Filled symbols passive diffusion constructs; open symbols active import (NLS) or active export (NES) constructs. *Estimated protein masses based on native PAGE (see S3 A). h/rCAT = EYFP-tagged human/rat catalase. NLS $=$ nuclear localization signal. PTS $=$ peroxisomal targeting signal. $\mathrm{mCh}=$ mCherry-tag. Scale bar $10 \mu \mathrm{m}$

PAGE revealed multiple bands for $\mathrm{r} / \mathrm{hCAT}$ indicating that the proteins were present in several oligomeric states (Fig. S3a), whereby rCAT and rCAT- $\triangle \mathrm{PTS}$ appeared to be primarily dimers $(175 \mathrm{kDa})$ and trimers $(263 \mathrm{kDa})$, and hCAT and hCAT- $\triangle$ PTS also formed tetramers $(\sim 349 \mathrm{kDa})$. The latter finding would explain the stronger nuclear exclusion of hCAT- $\triangle \mathrm{PTS}$. Due to the smaller size of dimeric/ trimeric $\mathrm{rCAT}-\triangle \mathrm{PTS}$ proteins, they have a higher mobility and efficiency in passing through NPCs (Baum et al. 2014); therefore, diffusion into the nucleus may be facilitated. Consequently, these findings provide evidence for a size-dependent decrease in passive diffusion. Indeed, while RNIs of constructs expected to passively diffuse (filled symbols) correlate nicely to protein mass, the RNIs of constructs showing active import $\left(\mathrm{RNI}_{\mathrm{NLS}-\mathrm{DAAO}}=1.79\right)$ or active export $\left(\mathrm{RNI}_{\mathrm{NES}-\mathrm{DAAO}}=0.67\right)$ do not fit the linear correlation (open symbols) (Fig. 3e). The fact that we obtained comparable results in WKPT (Fig. S3b, c) 
and U87 cells (data not shown) and the strong correlation between RNI and protein size ( $\mathrm{kDa}$ ) demonstrates the absence of a threshold for passive protein diffusion into the nucleus and a decrease of diffusion capability with protein mass.

Based on above premises, we hypothesized that newly synthesized, transiently cytosolic DAAO should also diffuse into the nucleus whilst being targeted to peroxisomes. We confirmed the inherent presence of nuclear DAAO (Fig. 4a) and CAT (data not shown), using confocal microscopy (constant laser power) at several timepoints after transfection, a finding also corroborated via Cellomics (Fig. 4b, control). Note that in confocal microscopy, the presence of nuclear proteins may easily be missed due to a dense, local fluorescence intensity in small compartments like peroxisomes (Fig. 4a, 72 h). Since only nuclear proteasome substrates accumulate in nuclear aggresomes after proteasome inhibition (Latonen et al. 2011), we treated transfected HEK293 cells with epoxomicin, a well-established proteasome inhibitor. We observed an accumulation of nuclear but not cytosolic DAAO and CAT, whereas the lysosomal inhibitor chloroquine had no effect (Fig. 4b; data not shown for CAT), contrasting earlier reports in U87 cells overexpressing EYFP-hDAAO (Cappelletti et al. 2014). Moreover, accumulations of EYFP-DAAO in HEK293 cells were found to be ubiquitinated, SUMOylated, and localized in close proximity to the nucleoli (Fig. 4c). These data suggest that DAAO is neither degraded via lysosomes nor via the cytosolic but rather the nuclear proteasomal degradation pathway. Consequently, nuclear "mislocalization" of peroxisomal proteins may represent a part of normal cell physiology that can be better observed in DAAO-overexpressing cells. However, cells can counteract mislocalized nuclear proteins by actively exporting them from the nucleus via exportins, e.g., CRM1 (Kirli et al. 2015). Thus, we asked whether or not DAAO can be actively exported from the nucleus and whether this mechanism is impaired when DAAO accumulates in the nucleus. However, despite that we found a putative and surfaceexposed nuclear export signal (NES) in DAAO, treatment
A

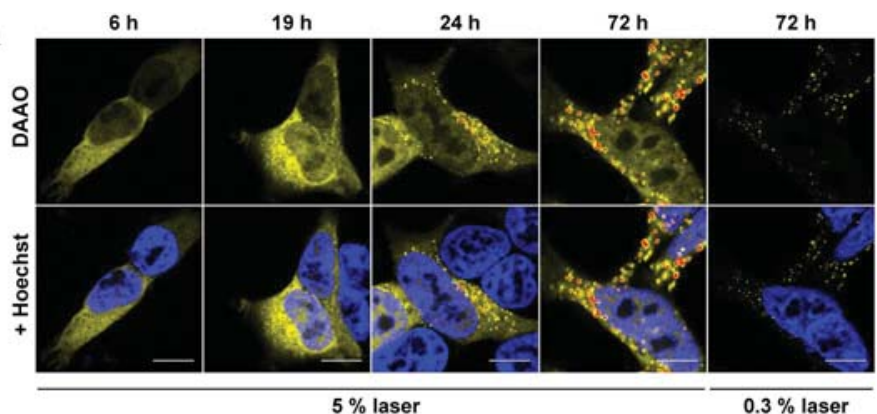

B

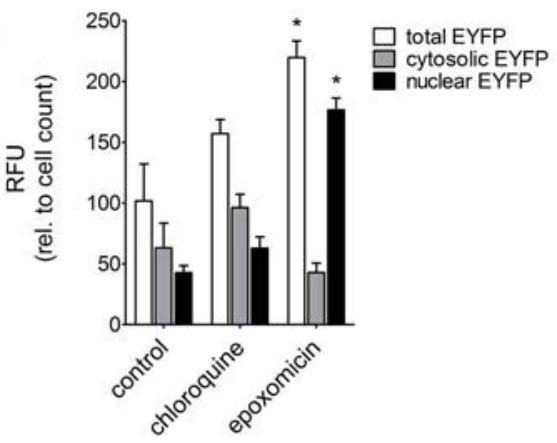

C

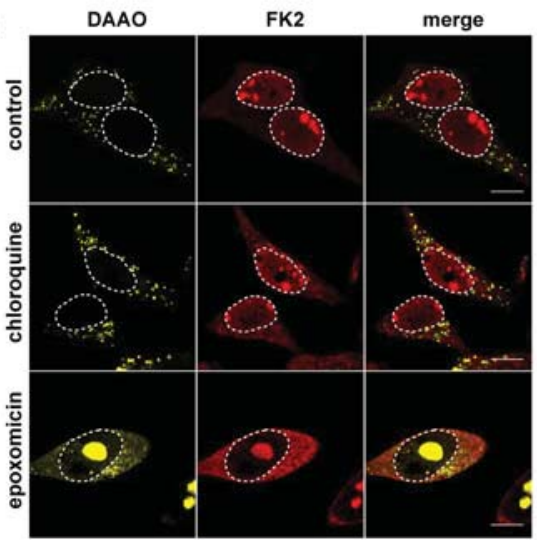

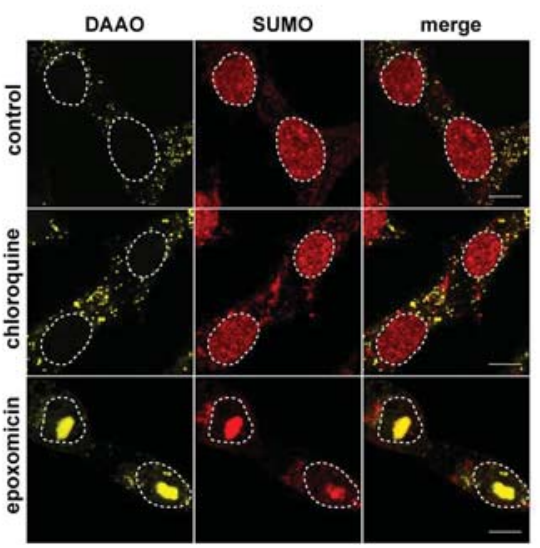

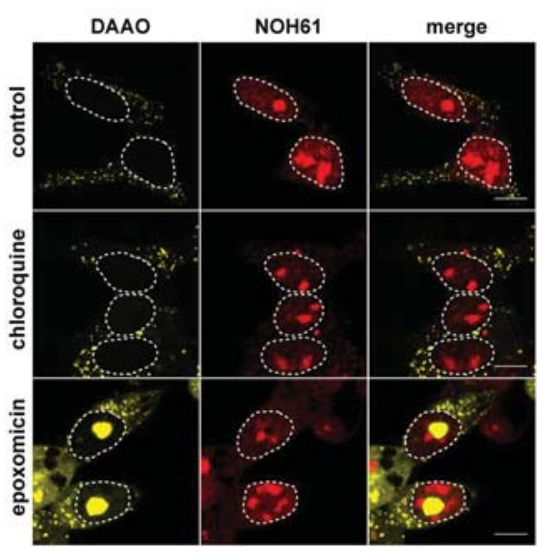

Fig. 4 DAAO is inherently present in the nucleus and forms nuclear aggresomes upon proteasome inhibition. a Confocal microscopy of transiently transfected HEK293 cells expressing EYFP-DAAO 6-72 h after transfection. Nuclei are labeled with Hoechst33342. Overexposed regions are marked in red. b Fluorescence intensity in EYFP-DAAO-HEK293 cells exposed to $50 \mu \mathrm{M}$ lysosomal inhibitor chloroquine or $1 \mu \mathrm{M}$ proteasomal inhibitor epoxomicin for $24 \mathrm{~h}$. Increase in EYFP signal was quantified using Cellomics and normalized to cell count. Mean $\pm \operatorname{SEM}, n=4$ with 6 technical replicates.
One-way ANOVA with Dunnett's post-test, $* p<0.01$. c Confocal microscopy of transiently transfected HEK293 cells expressing EYFP-DAAO treated with $50 \mu \mathrm{M}$ chloroquine or $0.5 \mu \mathrm{M}$ epoxomicin for $24 \mathrm{~h}$. Nuclei are indicated by dashed lines. Cells are stained for mono- and polyubiquitinylated conjugates (FK2), SUMOylation (SUMO) and nucleoli (NOH61). DAAO = EYFP-tagged human/rat DAAO. RFU $=$ relative fluorescence units. FK2 = mono- and polyubiquitinylated conjugates. SUMO = small ubiquitin-like modifier. $\mathrm{NOH61}=$ nucleolar helicase. Scale bar $10 \mu \mathrm{m}$ 

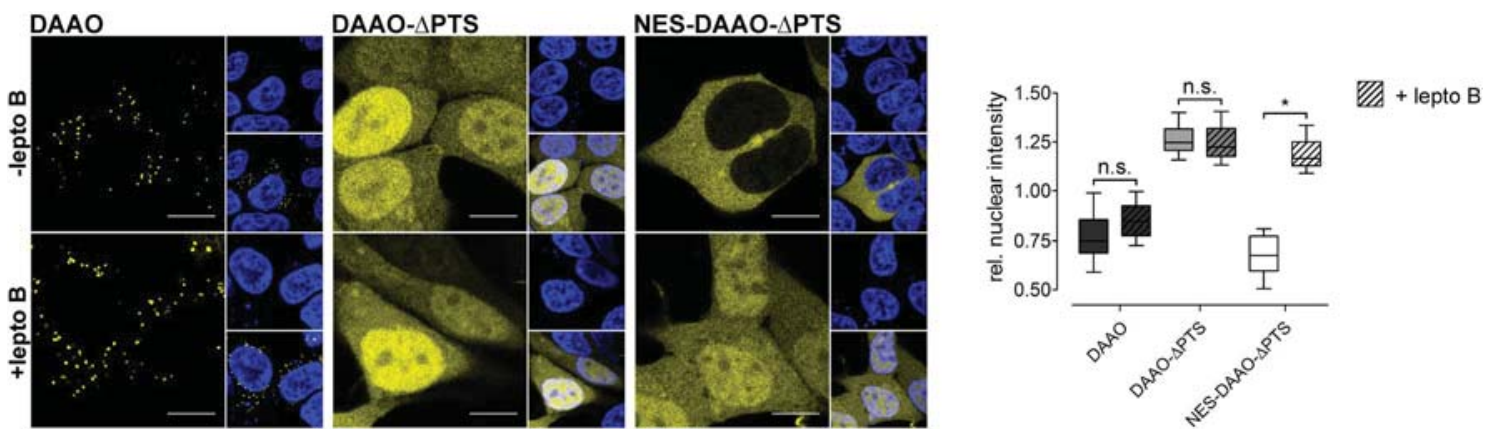

Fig. 5 Inhibition of nuclear export does not affect DAAO localization. Confocal microscopy and RNI of HEK293 cells transiently transfected with EYFP-DAAO and treated with $10 \mathrm{ng} / \mathrm{mL}$ leptomycin B for 2.5 h. Nuclei are labeled with Hoechst33342. Box-and-whisk-

of wild-type DAAO and DAAO- $\triangle \mathrm{PTS}$ with leptomycin $\mathrm{B}$, a potent CRM1 inhibitor, did not change localization of either DAAO construct (Fig. 5, black + gray bars). On the contrary, nuclear localization of DAAO- $\triangle \mathrm{PTS}$ containing a consensus NES sequence (Fig. 5, white bars) was significantly increased following treatment with leptomycin B. These results strongly suggest that DAAO contains no functional NES sequence that would counteract passive diffusion into the nucleus.

\section{Discussion}

Our study addressed the question how peroxisomal proteins, i.e., DAAO, end up accumulating in the nucleus of rat proximal tubule cells after pharmaceutical exposure. Since interference with the cyto-nuclear shuttling did not result in any change in DAAO distribution, we consider this particular mechanism unlikely to be involved in propiverine-induced pathology. However, we provide evidence that peroxisomal proteins, e.g., DAAO and CAT, are not exclusively localized in peroxisomes but are also continuously present in the nucleus as suggested previously (Kirli et al. 2015; Kolodney et al. 2015). This is further corroborated by our findings that wild-type DAAO and CAT are primarily degraded via the nuclear proteasome. Moreover, we were able to demonstrate that this nuclear presence is mediated via passive diffusion rather than by active import mechanisms. Indeed, contrary to other studies, we provide strong evidence that the often-cited size exclusion limit of $\sim 40 \mathrm{kDa}$ for passive diffusion into the nucleus in mammalian cells is most likely not stringent. Indeed, using bulky EYFP- and mCherry-fusion proteins having a natural tertiary structure, instead of using pearl-like GFP oligomers (Seibel et al. 2007; Wang and Brattain 2007) that might artificially facilitate the passage through nuclear pores, we were able to demonstrate the passive diffusion of larger ers plot shows median and 10-90 percentile, ns = not significant, $* p<0.0001$. DAAO = EYFP-tagged human/rat DAAO. PTS $=$ peroxisomal targeting signal. NES = nuclear export signal. Scale bar $10 \mu \mathrm{m}$

proteins into the nucleus. We observed a linear correlation between nuclear diffusion and protein mass. Thus, our data corroborate and complement the recently published "soft barrier" model for passive protein diffusion reported for yeast, defining that passive diffusion of large, complex molecules is not "leakage" but rather an inherent characteristic of the NPC (Timney et al. 2016). Moreover, verifying the activity of isolated DAAO- $\triangle$ PTS protein, we assume that EYFP-DAAO- $\triangle$ PTS is also active in cells, i.e., inside the nucleus. We suggest that cells can cope with nuclear mislocalization of $\mathrm{H}_{2} \mathrm{O}_{2}$-producing proteins, since a nucleartargeted DAAO mutant (NLS-DAAO) was demonstrated to produce increased nuclear ROS levels yet without concurrent cytotoxicity (Halvey et al. 2007), a fact corroborated with our DAAO- $\triangle$ PTS mutants showing no elevated cytotoxicity in the presence of D-amino acids (data not shown). Since only mild cell shedding and mild regenerative proliferation was observed in vivo yet without concomitantly increased renal proximal tumor incidences (Dietrich et al. 2008), it would appear unlikely that mislocalized peroxisomal DAAO in renal proximal cells results in overt cytotoxicity or sublethal DNA damage with subsequent increased mutation rates.

Of importance is also the recent finding that PEX5, the cytosolic receptor of PTS1 proteins, was identified as a CRM1 cargo, allowing not only the rapid export of mislocalized nuclear PEX5 alone but likely also co-transport of PEX5-PTS1 protein complexes (Kirli et al. 2015). Still, our data show that inhibition of the nuclear export machinery did not affect DAAO localization, thereby indicating that nuclear export is most likely not involved in the formation of nuclear accumulations in vivo. In contrast, inhibition of the peroxisomal import did result in more intense nuclear DAAO localization in our cell systems. Therefore, we suggest that any influence on the peroxisomal import machinery or peroxins by pharmaceuticals (propiverine, NSRI) could lead to a local protein overload that exceeds the 
degradation capacity within the nucleus. Therefore, cells start to compartmentalize the protein as a common stress response (Tyedmers et al. 2010) resulting in dense accumulations as observed in vivo subsequent to pharmaceutical treatment or after inhibition of the proteasomal degradation in vitro. Upon cessation of drug exposure, i.e., when the system has regained sufficient capacity to deal with the protein overload (Latonen 2011), the nucleus will be cleared from accumulations. Indeed, drug-induced DAAO accumulations were proven to be reversible (Nakano et al. 1989; Yamashita et al. 1990). In conclusion, we suggest that drug-induced protein accumulations in rat proximal tubule cells in vivo arise from a reversible interference with the peroxisomal import machinery.

Acknowledgements This work was supported by the University of Konstanz and the Konstanz Research School Chemical Biology (KoRS-CB), the Deutsche Forschungsgemeinschaft (RTG 1331), and the Fondo di Ateneo per la Ricerca. We thank the Bioimaging Center (University of Konstanz) for the use of the imaging equipment. We acknowledge Prof. Dr. Frank Thevenod (University of Witten/Herdecke, Germany) for providing WKPT cells. Special thanks to Johannes Delp and Prof. Dr. Marcel Leist for providing instrumentation and support with Cellomics. We thank Dr. Sascha Beneke and Philipp Secker for helpful discussions and our students Nadja Schlichenmaier, Madeline Walz, and Céline Weller for assistance with cloning.

Author contributions L. Luks and M. Y. Maier planned the project, designed the experiments, performed all experiments except for the U87 data, analyzed, interpreted and visualized all data, wrote the original draft, and reviewed the manuscript. D. R. Dietrich provided resources, planned the project, and was involved in writing, reviewing, and editing the manuscript. S. Sacchi and L. Pollegioni provided resources and materials, performed the experiments with U87 cells, and were involved in editing the manuscript.

\section{Compliance with ethical standards}

Conflict of interest The authors declare that they have no conflict of interest.

Ethical standards The manuscript does not contain clinical studies or patient data.

\section{References}

Ast J, Stiebler AC, Freitag J, Bolker M (2013) Dual targeting of peroxisomal proteins. Front Physiol 4:297

Baudhuin P, Müller M, Poole B, de Duve C (1965) Non-mitochondrial oxidizing particles (microbodies) in rat liver and kidney and in Tetrahymena pyriformis. Biochem Biophys Res Commun 20:53-59

Baum M, Erdel F, Wachsmuth M, Rippe K (2014) Retrieving the intracellular topology from multi-scale protein mobility mapping in living cells. Nat Commun 5:4494

Bogerd HP, Fridell RA, Benson RE, Hua J, Cullen BR (1996) Protein sequence requirements for function of the human T-cell leukemia virus type 1 Rex nuclear export signal delineated by a novel in vivo randomization-selection assay. Mol Cell Biol 16:4207-4214

Caldinelli L, Molla G, Sacchi S, Pilone MS, Pollegioni L (2009) Relevance of weak flavin binding in human D-amino acid oxidase. Protein Sci 18:801-810

Cappelletti P, Campomenosi P, Pollegioni L, Sacchi S (2014) The degradation (by distinct pathways) of human D-amino acid oxidase and its interacting partner pLG72-two key proteins in D-serine catabolism in the brain. FEBS J 281:708-723

Chuderland D, Konson A, Seger R (2008) Identification and characterization of a general nuclear translocation signal in signaling proteins. Mol Cell 31:850-861

Ciesla J, Fraczyk T, Rode W (2011) Phosphorylation of basic amino acid residues in proteins: important but easily missed. Acta Biochim Pol 58:137-148

Dietrich DR, Heussner AH, O'Brien E, Gramatté T, Runkel M, Rumpf S, Day BW (2008) Propiverine-induced accumulation of nuclear and cytosolic protein in F344 rat kidneys: isolation and identification of the accumulating protein. Toxicol Appl Pharmacol 233:411-419

Edelheit O, Hanukoglu A, Hanukoglu I (2009) Simple and efficient site-directed mutagenesis using two single-primer reactions in parallel to generate mutants for protein structure-function studies. BMC Biotechnol 9:61

Elgersma Y, Vos A, van den Berg M, van Roermund CW, van der Sluijs P, Distel B, Tabak HF (1996) Analysis of the carboxyl-terminal peroxisomal targeting signal 1 in a homologous context in Saccharomyces cerevisiae. J Biol Chem 271:26375-26382

Frattini LF, Piubelli L, Sacchi S, Molla G, Pollegioni L (2011) Is rat an appropriate animal model to study the involvement of D-serine catabolism in schizophrenia? insights from characterization of D-amino acid oxidase. FEBS J 278:4362-4373

Fried H, Kutay U (2003) Nucleocytoplasmic transport: taking an inventory. Cell Mol Life Sci 60:1659-1688

Garcia-Mata R, Bebok Z, Sorscher EJ, Sztul ES (1999) Characterization and dynamics of aggresome formation by a cytosolic GFP-chimera. J Cell Biol 146:1239-1254

Gould SJ, Keller GA, Subramani S (1988) Identification of peroxisomal targeting signals located at the carboxy terminus of four peroxisomal proteins. J Cell Biol 107:897-905

Halvey PJ, Hansen JM, Johnson JM, Go YM, Samali A, Jones DP (2007) Selective oxidative stress in cell nuclei by nuclear-targeted D-amino acid oxidase. Antioxid Redox Signal 9:807-816

Henn A, Kirner S, Leist M (2011) TLR2 hypersensitivity of astrocytes as functional consequence of previous inflammatory episodes. J Immunol 186:3237-3247

Hung MC, Link W (2011) Protein localization in disease and therapy. J Cell Sci 124:3381-3392

Kalderon D, Richardson WD, Markham AF, Smith AE (1984a) Sequence requirements for nuclear location of simian virus 40 large-T antigen. Nature 311:33-38

Kalderon D, Roberts BL, Richardson WD, Smith AE (1984b) A short amino acid sequence able to specify nuclear location. Cell 39:499-509

Keminer O, Peters R (1999) Permeability of single nuclear pores. Biophys J 77:217-228

Kırlı K, Karaca S, Dehne HJ, Samwer M, Pan KT, Lenz C, Urlaub H, Görlich D (2015) A deep proteomics perspective on CRM1mediated nuclear export and nucleocytoplasmic partitioning. Elife. doi:10.7554/eLife.11466

Knockenhauer Kevin E, Schwartz Thomas U (2016) The nuclear pore complex as a flexible and dynamic gate. Cell 164:1162-1171

Kolodney G, Dumin E, Safory H, Rosenberg D, Mori H, Radzishevsky I, Wolosker H (2015) Nuclear compartmentalization of 
serine racemase regulates D-Serine production: implications for $N$-methyl- $D$-aspartate (NMDA) receptor activation. J Biol Chem 290:31037-31050

Latonen L (2011) Nucleolar aggresomes as counterparts of cytoplasmic aggresomes in proteotoxic stress. Proteasome inhibitors induce nuclear ribonucleoprotein inclusions that accumulate several key factors of neurodegenerative diseases and cancer. BioEssays 33:386-395

Latonen L, Moore HM, Bai B, Jaamaa S, Laiho M (2011) Proteasome inhibitors induce nucleolar aggregation of proteasome target proteins and polyadenylated RNA by altering ubiquitin availability. Oncogene 30:790-805

Lazarow PB, de Duve C (1973) The synthesis and turnover of rat liver peroxisomes: IV. Biochemical pathway of catalase synthesis. J Cell Biol 59:491-506

Luks L, Sacchi S, Pollegioni L, Dietrich DR (2017) Novel insights into renal D-amino acid oxidase accumulation: propiverine changes DAAO localization and peroxisomal size in vivo. Arch Toxicol 91:427-437

Ma J, Goryaynov A, Sarma A, Yang W (2012) Self-regulated viscous channel in the nuclear pore complex. Proc Natl Acad Sci 109:7326-7331

Mitchell J, Paul P, Chen H-J, Morris A, Payling M, Falchi M, Habgood J, Panoutsou S, Winkler S, Tisato V, Hajitou A, Smith B, Vance C, Shaw C, Mazarakis ND, de Belleroche J (2010) Familial amyotrophic lateral sclerosis is associated with a mutation in D-amino acid oxidase. Proc Natl Acad Sci 107(16):7556-7561

Molla G, Sacchi S, Bernasconi M, Pilone MS, Fukui K, Polegioni L (2006) Characterization of human D-amino acid oxidase. FEBS Lett 580:2358-2364

Nakano S, Kuwata M, Hasegawa H, Irimura K, Maruden A, Morita K (1989) Thirteen-week oral toxicity study of propiverine hydrochloride in rats. J Toxicol Sci 14(Suppl 2):13-59

Paine PL, Feldherr CM (1972) Nucleocytoplasmic exchange of macromolecules. Exp Cell Res 74:81-98

Park S-H, Kukushkin Y, Gupta R, Chen T, Konagai A, Hipp MS, Hayer-Hartl M, Hartl FU (2013) PolyQ proteins interfere with nuclear degradation of cytosolic proteins by sequestering the Sis1p chaperone. Cell 154:134-145

Purdue PE, Lazarow PB (1996) Targeting of human catalase to peroxisomes is dependent upon a novel $\mathrm{COOH}$-terminal peroxisomal targeting sequence. J Cell Biol 134:849-862

Radi ZA, Stewart ZS, Grzemski FA, Bobrowski WF (2013) Renal pathophysiologic role of cortical tubular inclusion bodies. Toxicol Pathol 41:32-37
Romano D, Molla G, Pollegioni L, Marinelli F (2009) Optimization of human D-amino acid oxidase expression in Escherichia coli. Protein Expr Purif 68:72-78

Sacchi S, Bernasconi M, Martineau M, Mothet J-P, Ruzzene M, Pilone MS, Pollegioni L, Molla G (2008) pLG72 modulates intracellular D-Serine levels through its interaction with D-amino acid oxidase: effect on schizophrenia susceptibility. J Biol Chem 283:22244-22256

Sacchi S, Cappelletti P, Giovannardi S, Pollegioni L (2011) Evidence for the interaction of D-amino acid oxidase with pLG72 in a glial cell line. Mol Cell Neurosci 48:20-28

Seibel NM, Eljouni J, Nalaskowski MM, Hampe W (2007) Nuclear localization of enhanced green fluorescent protein homomultimers. Anal Biochem 368:95-99

Smith JJ, Aitchison JD (2013) Peroxisomes take shape. Nat Rev Mol Cell Biol 14:803-817

Timney BL, Raveh B, Mironska R, Trivedi JM, Kim SJ, Russel D, Wente SR, Sali A, Rout MP (2016) Simple rules for passive diffusion through the nuclear pore complex. J Cell Biol 215(1):57-76

Trelease RN, Xie W, Lee MS, Mullen RT (1996) Rat liver catalase is sorted to peroxisomes by its C-terminal tripeptide Ala-AsnLeu, not by the internal Ser-Lys-Leu motif. Eur J Cell Biol $71: 248-258$

Tyedmers J, Mogk A, Bukau B (2010) Cellular strategies for controlling protein aggregation. Nat Rev Mol Cell Biol 11:777-788

Vainshtein BK, Melik-Adamyan WR, Barynin VV, Vagin AA, Grebenko AI (1981) Three-dimensional structure of the enzyme catalase. Nature 293:411-412

Verrall L, Walker M, Rawlings N, Benzel I, Kew JNC, Harrison PJ, Burnet PWJ (2007) D-amino acid oxidase and serine racemase in human brain: normal distribution and altered expression in schizophrenia. Eur J Neurosci 26:1657-1669

Verrall L, Burnet PW, Betts JF, Harrison PJ (2010) The neurobiology of D-amino acid oxidase and its involvement in schizophrenia. Mol Psychiatry 15:122-137

Wang R, Brattain MG (2007) The maximal size of protein to diffuse through the nuclear pore is larger than $60 \mathrm{kDa}$. FEBS Lett 581:3164-3170

Yamashita K, Kuwata M, Irimura K, Morinaga N, Kurokawa K, Ashizawa M (1990) Fifty-two-weeks oral chronic toxicity study of propiverine hydrochloride in rats. J Toxicol Sci 15:107-144 